\title{
Survival outcome of combined GnRH agonist and tamoxifen is comparable to that of sequential adriamycin and cyclophosphamide chemotherapy plus tamoxifen in premenopausal patients with early breast cancer
}

\author{
DOONYAPAT SA-NGUANRAKSA ${ }^{1}$, THITIKON KRISORAKUN ${ }^{1,2}$, \\ WANEE PONGTHONG $^{1}$ and PORNCHAI O-CHAROENRAT ${ }^{1}$ \\ ${ }^{1}$ Division of Head Neck and Breast Surgery, Department of Surgery, Faculty of Medicine, Siriraj Hospital, \\ Mahidol University, Bangkok 10700; ${ }^{2}$ Department of Surgery, Rajavithi Hospital, Bangkok 10400, Thailand
}

Received February 4, 2019; Accepted June 10, 2019

DOI: 10.3892/mco.2019.1913

\begin{abstract}
Survival outcome of ovarian suppression plus tamoxifen has been shown to be comparable with chemotherapy in premenopausal women; however, there are a few previous studies that compared this treatment to the current standard adriamycin and cyclophosphamide (AC) regimen. The aim of the present study was to compare the survival outcome of gonadotropin-releasing hormone $(\mathrm{GnRH})$ agonist plus tamoxifen (GnRH-TAM) and chemotherapy AC plus tamoxifen (AC-TAM) in premenopausal patients with early breast cancer who were hormone receptor-positive. Premenopausal patients with early breast cancer who were treated at The Siriraj Hospital between January 2005 and December 2015 were retrospectively recruited. The inclusion criteria included newly diagnosed breast cancer, size $\leq 3 \mathrm{~cm}$, node-negative and hormone receptor-positive. All patients received adjuvant systemic therapy and were divided into two groups. In the GnRH-TAM group, the patients received subcutaneous injection of $10.8 \mathrm{mg}$ of goserelin every 3 months for 2-3 years and TAM $(20 \mathrm{mg} /$ day $)$ for 5 years. In the AC-TAM group, AC was administered
\end{abstract}

Correspondence to: Professor Pornchai O-Charoenrat, Division of Head Neck and Breast Surgery, Department of Surgery, Faculty of Medicine, Siriraj Hospital, Mahidol University, 2 Wanglang Road Bangkoknoi, Bangkok 10700, Thailand

E-mail: pornchai.och@mahidol.ac.th

Abbreviations: AC, adriamycin and cyclophosphamide; TAM, tamoxifen; GnRH-TAM, gonadotropin-releasing hormone agonist plus tamoxifen; AC-TAM, adriamycin and cyclophosphamide plus tamoxifen; TC, docetaxel and cyclophosphamide; CMF, cyclophosphamide, methotrexate and fluorouracil; OS, overall survival; DFS, disease-free survival

Key words: early breast cancer, endocrine therapy, ovarian suppression, gonadotropin-releasing hormone agonist, premenopause every 3 weeks for 4 cycles followed by TAM $(20 \mathrm{mg} /$ day $)$ for 5 years. In total, 40 patients received GnRH-TAM and 130 patients received AC-TAM. The mean age at diagnosis was $44.4 \pm 6.3$ years while the median follow up time was 77 (36-167) months. There was no mortality in either group and no significant difference in disease-free survival between the two groups. No adverse effect occurred and good compliance was observed in all patients who received GnRH-TAM. Treatment with GnRH-TAM resulted in a comparable survival outcome and better quality of life compared with AC-TAM.

\section{Introduction}

Breast cancer is the most frequent cancer among women worldwide (1). The proportion of patients with breast cancer, who were younger than 50 years appears to be higher in Asian women compared with Western women (2). In Thailand, more than one-half of patients with breast cancer were diagnosed at an age younger than 50 years $(3,4)$. In total, $\sim 54 \%$ of breast cancer is hormone receptor-positive and the proportion is decreased in younger patients $(3,5)$.

Endocrine therapy, either alone or after chemotherapy, is the most important treatment in hormone receptor-positive breast cancer. Blockage of the oestrogen receptor (ER) and its pathways is a key approach for the treatment of hormone receptor-positive breast cancer (6). Tamoxifen (TAM) is a standard endocrine therapy, especially in premenopausal women (7). In post-menopausal women, administration of aromatase inhibitors results in better survival compared with TAM $(8,9)$. Ovarian ablation plus chemotherapy resulted in improved long-term survival in ER-positive early breast cancer (10). When comparing the cyclophosphamide, methotrexate and fluorouracil regimen (CMF) of chemotherapy with ovarian ablation/suppression, there was no difference in terms of survival in hormone receptor-positive early breast cancer (11-16). However, to the best of our knowledge, at present, there is no randomised controlled trial that has compared ovarian function suppression and TAM with the adriamycin and cyclophosphamide (AC) regimen of 
chemotherapy. The addition of ovarian function suppression to TAM in women who were premenopausal after chemotherapy resulted in a better disease outcome (17).

The present study aimed to compare disease-free survival (DFS) and overall survival (OS) in patients with early breast cancer who received gonadotropin-releasing hormone (GnRH) agonist-TAM (GnRH-TAM) alone compared with those who received chemotherapy followed by TAM (AC-TAM).

\section{Patients and methods}

Patients. Female patients with breast cancer who were treated at The Division of Head Neck and Breast Surgery, Department of Surgery, Faculty of Medicine, Siriraj Hospital, Mahidol University (Bangkok, Thailand) between January 2005 and December 2015 were recruited. The inclusion criteria were premenopausal status, tumour size $\leq 3 \mathrm{~cm}$, node-negative, no distant metastasis, hormone receptor-positive and did not receive neoadjuvant treatment. The patients who rejected adjuvant chemotherapy received GnRH-TAM were recruited in the GnRH-TAM group. The patients who received AC-TAM were recruited in the AC-TAM group. The patients with incomplete clinicopathological data were excluded. Medical records of the eligible patients were reviewed. Premenopausal status was defined as those who had menstruated within 1 year before surgery or had a follicle-stimulating hormone level $<30$ IU/ml. All of the patients who received GnRH-TAM without adjuvant chemotherapy were included. The patients who received standard AC-TAM with comparable demographic and clinicopathological parameters were recruited. The tumor grade was classified according to Elston/Nottingham modification of the Bloom-Richardson System $(18,19)$. The follow-up time was 36-167 months with a median follow-up of 77 months. The sample size was calculated using the two proportions formula for a non-inferiority test (20). The parameters included in the formula were as follows: i) The expected survival was 0.98 and 0.96 for AC-TAM and GnRH-TAM, respectively; ii) one-sided significance level, 0.05 ; iii) the power of test, 0.8 ; iv) non-inferiority margin, 0.06 ; and v) the ratio of sample size, 3. This resulted in a calculated sample size of 120 patients who received AC-TAM and 40 patients who received GnRH-TAM. During the recruitment period, 130 patients who received AC-TAM and 40 patients who received GnRH-TAM met the inclusion criteria. All of the patients had complete follow-up data. The present study was approved by The Siriraj Institutional Review Board (certificate of approval no. Si 674/2016). No informed consent was obtained from the patients as the present study was retrospective in nature.

Treatment. In the GnRH-TAM group, the patients received subcutaneous injection of $10.8 \mathrm{mg}$ goserelin every 3 months for 2-3 years and TAM (20 mg/day) for 5 years. In the AC-TAM group, AC was administered every 3 weeks for 4 cycles $\left(60 \mathrm{mg} / \mathrm{m}^{2}\right.$ adriamycin intravenously plus $60 \mathrm{mg} / \mathrm{m}^{2}$ cyclophosphamide intravenously every 21 days) followed by TAM (20 mg/day) for 5 years.

Statistical analysis. Continuous parameters are presented as the mean \pm SD. Categorical parameters are presented as the frequency and percentage. The DFS period was defined as the time from the operation to disease recurrence or death (whichever occurred first) and the OS period was defined as the time from the operation to death from any cause. The categorical characteristics of the patients were compared between the two treatment groups using Pearson's $\chi^{2}$ test. The continuous parameters of the two treatment groups were compared using independent t-test. DFS and OS were assessed using Kaplan-Meier curves and compared using a log-rank test. The Cox proportional hazards model was used to calculate the adjusted hazard ratios. $\mathrm{P}<0.05$ was considered to indicate a statistically significant difference. The statistical analysis was performed using SPSS software version 21 (IBM Corp.).

\section{Results}

Patients and tumour characteristics. The total number of the patients recruited was 170 . The mean age at diagnosis was $44.4 \pm 6.3$ years. In total, 40 patients received GnRH-TAM and 130 patients received AC-TAM. The baseline characteristics of the patients, tumours and treatments are presented in Table I. There was no significant difference in all pathological parameters. All patients with HER2 overexpression had a tumour size $<2 \mathrm{~cm}$ and did not receive HER2-targeted therapy. In the GnRH-TAM group, a higher proportion of the patients underwent breast-conserving surgery followed by postoperative radiotherapy. All of the patients in the GnRH-TAM group experienced hot flashes but could tolerate and received complete treatment. Most of the patients in the AC-TAM group had common side effects of chemotherapy, including alopecia and nausea. No severe adverse effects, such as cardiotoxicity were observed in the AC-TAM group.

Survival analysis. The median follow-up time was 77 (36-167) months. There was no death that occurred during the follow-up period. Only one local recurrence in the conserved breast occurred in the GnRH-TAM group at 48 months after surgery. In the AC-TAM group, there were 3 patients with loco-regional recurrence of the conserved breast, chest wall and axillary lymph nodes at 37, 47 and 120 months after surgery, respectively. Additionally, in the AC-TAM group, 1 patient had lung metastasis and another patient had lung and liver metastasis at 66 and 149 months, respectively. Survival analysis by Kaplan-Meier method revealed no difference in DFS for each parameter (Table II). OS analysis was not conducted in the present study as all patients survived and there was no death in the follow-up period. Multivariate analysis by Cox regression showed that lymphovascular invasion tended to be an independent prognostic factor for lower DFS; however, this was not significant. The survival curves of DFS by each treatment group showed no significant difference between the GnRH-TAM group and AC-TAM group ( $\mathrm{P}=0.858$; Fig. 1).

\section{Discussion}

Hormonal therapy after chemotherapy or hormonal therapy alone is the main treatment option in hormone receptor-positive, HER2-negative early breast cancer (7). The decision of treatment depends on the aggressiveness of the disease and 
Table I. Characteristics of the patients.

\begin{tabular}{|c|c|c|c|}
\hline Characteristics & GnRH-TAM, n=40 n (\%) & AC-TAM, n=130 n (\%) & P-value \\
\hline Age, mean \pm SD (years) & $45.1 \pm 3.5$ & $44.2 \pm 6.9$ & $0.30^{\mathrm{a}}$ \\
\hline \multicolumn{4}{|l|}{ Tumour size } \\
\hline$\leq 20 \mathrm{~mm}$ & $30(75.0)$ & $91(70.0)$ & \multirow[t]{2}{*}{0.54} \\
\hline$>20 \mathrm{~mm}$ & $10(25.0)$ & $39(30.0)$ & \\
\hline \multicolumn{4}{|l|}{ Histology } \\
\hline Invasive ductal carcinoma & $40(100.0)$ & $123(94.6)$ & \multirow[t]{2}{*}{0.13} \\
\hline Invasive lobular carcinoma & 0 & $7(5.4)$ & \\
\hline \multicolumn{4}{|l|}{ Tumour grade } \\
\hline Grade 1 & $13(33.3)$ & $23(17.7)$ & \multirow[t]{3}{*}{0.11} \\
\hline Grade 2 & $23(59.0)$ & $97(74.6)$ & \\
\hline Grade 3 & $3(7.7)$ & $10(7.7)$ & \\
\hline \multicolumn{4}{|l|}{ Lymphovascular invasion } \\
\hline No & $36(90.0)$ & $122(93.8)$ & \multirow[t]{2}{*}{0.41} \\
\hline Yes & $4(10.0)$ & $8(6.2)$ & \\
\hline \multicolumn{4}{|l|}{ HER2 } \\
\hline Negative & $37(92.5)$ & $109(83.8)$ & \multirow[t]{2}{*}{0.17} \\
\hline Positive & $3(7.5)$ & $21(16.2)$ & \\
\hline \multicolumn{4}{|l|}{ Type of surgery } \\
\hline Breast conserving surgery & $27(67.5)$ & $56(43.1)$ & \multirow[t]{2}{*}{0.01} \\
\hline Total mastectomy & $13(32.5)$ & $74(56.9)$ & \\
\hline
\end{tabular}

andependent t-test. HER2, human epidermal growth factor receptor 2; GnRH-TAM, gonadotropin-releasing hormone agonist plus tamoxifen; AC-TAM, adriamycin and cyclophosphamide plus tamoxifen.

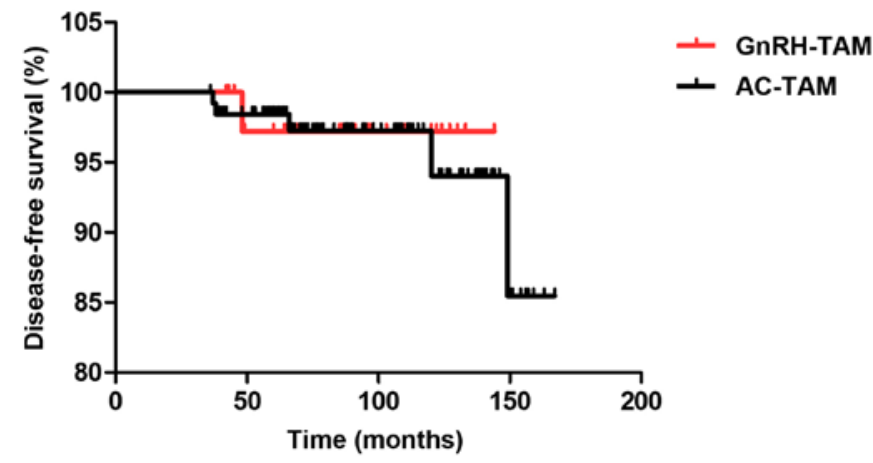

Figure 1. DFS of the treatment groups. There was no difference in DFS between the two groups. The GnRH-TAM group had slightly higher DFS than the AC-TAM group. DFS, disease-free survival; GnRH-TAM, gonadotropin-releasing hormone agonist plus tamoxifen; AC-TAM, adriamycin and cyclophosphamide plus tamoxifen.

the condition of the patients. In the present study, patients with breast cancer were recruited, who completely rejected chemotherapy due to concerns for quality of life. GnRH-TAM did not demonstrate inferior survival when compared with AC-TAM in hormone receptor-positive, HER2-negative early breast cancer.

Ovarian function suppression has been shown to improve the outcome of high-risk premenopausal patients when combined with TAM, but this benefit was not established in a low-risk group (17). Only a few previous studies, to the best of our knowledge, have illustrated that GnRH agonists are suitable substitutes for chemotherapy in hormone-responsive patients with breast cancer $(21,22)$. Meta-analysis by Early Breast Cancer Trialist's Collaborative Group showed that patients with breast cancer under the age of 50 years who received ablation of ovarian function had better long-term survival regardless of hormone receptor status $(10,23)$. In premenopausal women with hormone receptor-positive breast cancer, ovarian function suppression plus TAM resulted in increased 8-year DFS and OS rates (24). Subgroup analysis showed that in the patients who did not receive prior chemotherapy, the favourable outcome was more emphasized (24). The effect of ovarian ablation in the improvement of survival was more influential in the patients who did not receive chemotherapy; chemotherapy may itself suppress ovarian function in late premenopausal women.

Several previous randomised control trials compared ovarian function suppression/ovarian ablation to CMF alone in hormone receptor-positive premenopausal patients with early breast cancer there was no difference between the two treatment regimens in DFS and OS $(22,25-31)$. The efficacy of ovarian function suppression or ovarian ablation is similar to that of chemotherapy and may replace chemotherapy as an alternative choice of treatment. Previous randomised control trials compared medical ovarian function ablation using a GnRH agonist with CMF in hormone receptor-positive premenopausal women, and found no difference in both DFS and OS (26-28,31). This finding was observed in 
Table II. Disease-free survival among different parameters and treatment groups.

\begin{tabular}{|c|c|c|c|c|c|c|c|}
\hline Parameters & Case & Event & 5-year survival & 10 -year survival & P-value & $\begin{array}{c}\text { Hazard ratio } \\
(95 \% \mathrm{CI})\end{array}$ & P-value ${ }^{b}$ \\
\hline \multicolumn{8}{|l|}{ Age at diagnosis } \\
\hline$\leq 45$ years & 91 & 3 & 1.00 & 0.93 & 0.85 & $1.54(0.27-8.82)$ & 0.63 \\
\hline$>45$ years & 79 & 3 & 0.96 & 0.96 & & & \\
\hline \multicolumn{8}{|l|}{ Tumour size } \\
\hline$\leq 20 \mathrm{~mm}$ & 121 & 4 & 0.98 & 0.94 & 0.93 & $1.01(0.17-5.88)$ & 0.99 \\
\hline$>20 \mathrm{~mm}$ & 49 & 2 & 0.98 & 0.95 & & & \\
\hline \multicolumn{8}{|l|}{ Tumour grade } \\
\hline Grade 1 & 36 & 0 & 1.00 & 1.00 & 0.19 & N/A & 0.98 \\
\hline Grade $2 / 3$ & 133 & 6 & 0.98 & 0.93 & & & \\
\hline \multicolumn{8}{|c|}{ Lymphovascular invasion } \\
\hline Absence & 158 & 4 & 0.99 & 0.98 & 0.06 & $4.78(0.84-27.29)$ & 0.08 \\
\hline Presence & 12 & 2 & 0.92 & 0.76 & & & \\
\hline \multicolumn{8}{|l|}{ HER2 status } \\
\hline Negative & 146 & 6 & 0.98 & 0.94 & 0.44 & N/A & 0.99 \\
\hline Positive & 24 & 0 & 1.00 & 1.00 & & & \\
\hline \multicolumn{8}{|l|}{ Surgery } \\
\hline Breast conserving & 83 & 4 & 0.97 & 0.90 & 0.22 & $0.29(0.04-1.89)$ & 0.20 \\
\hline Total mastectomy & 87 & 2 & 0.99 & 0.99 & & & \\
\hline \multicolumn{8}{|l|}{ Systemic treatment } \\
\hline GnRH-TAM & 40 & 1 & 0.97 & 0.97 & 0.86 & $1.90(0.19-18.80)$ & 0.58 \\
\hline AC-TAM & 130 & 5 & 0.98 & 0.94 & & & \\
\hline
\end{tabular}

${ }^{\mathrm{a}} \mathrm{Log}$ rank test; ${ }^{\mathrm{b}} \mathrm{Cox}$ regression. N/A, not available as very few events occurred. HER2, human epidermal growth factor receptor 2; GnRH-TAM, gonadotropin-releasing hormone agonist plus tamoxifen; AC-TAM, adriamycin and cyclophosphamide plus tamoxifen.

both node-negative patients $(27,31)$ and node-positive patients $(26,28)$. However, patients who received GnRH agonist alone demonstrated better quality of life compared with those who received adjuvant chemotherapy (32-34). Several previous studies compared a combination of ovarian function suppression plus TAM to chemotherapy alone in hormone receptor positive, premenopausal early breast cancer. The results suggested that combined endocrine therapy is a reasonable alternative to chemotherapy $(15,16,35,36)$. Furthermore, in hormone receptor-positive patients, administration of $3.6 \mathrm{mg}$ goserelin every 4 weeks for 3 years plus TAM for 5 years was more effective than CMF (15). In terms of quality of life, the patients receiving $\mathrm{GnRH}$ analog had less deterioration in quality of life over the first 6 months when compared with those receiving the CMF regimen (37). In the present study, the patients who received GnRH-TAM had no adverse effects and were able to complete the course of treatment. In addition, the patients in the GnRH-TAM group could avoid the side-effects of chemotherapy, including alopecia, permanent infertility, chemotherapy-induced memory problems and febrile neutropenia (38).

To the best of our knowledge, at present, there is no randomised controlled trial that compared combined ovarian function suppression and TAM with sequential AC-TAM. The present retrospective study found comparable survival outcome between these two treatment regimens similar to other previous retrospective studies of a Korean population $(39,40)$. There was only one local recurrence in the GnRH-TAM group while in the AC-TAM group, 2 patients with distant metastasis were identified. No mortality occurred in the enrolled patients. Further long-term follow-up might be required for luminal subtype breast cancer.

Cost-utility analysis of GnRH agonist and adjuvant chemotherapy showed that GnRH agonist is more cost-effective than the docetaxel cyclophosphamide (TC) regimen (41). However, in Thailand, TC is reserved for the patients who have a higher risk for cardiotoxicity when they receive the $\mathrm{AC}$ regimen due to cumulative dose-related and permanent cardiotoxicity of anthracycline (42), and the higher cost of a TC regimen. Administration of $10.8 \mathrm{mg}$ goserelin every 3 months as in the present study is convenient, reduces costs, with no adverse effects. The efficacy of ovarian function suppression was comparable to $3.6 \mathrm{mg}$ monthly doses (43). The present study indicated that $10.8 \mathrm{mg} 3$-monthly administration of goserelin does not result in a different outcome, and is safe and practical to use.

There are limitations to the present study; it is a retrospective study conducted in a single institute with a limited number of patients in GnRH-TAM group. This may cause selection bias in the analysis. According to The National Comprehensive Cancer Network Clinical Practice Guideline (version 3.2018) (7), this group of patients should be evaluated 
by a 21-gene reverse transcription-PCR assay to classify the risk of recurrence. Further studies including this assay might be beneficial and a multicentre-randomised controlled study is required for the prospective comparison of the efficacies of GnRH-TAM and AC-TAM regimens in premenopausal patients with early stage breast cancer.

In conclusion, it was demonstrated that in premenopausal women with hormone receptor-positive, node-negative early breast cancer, adjuvant treatment with GnRH-TAM had similar survival outcomes and improved the quality of life compared with patients who were treated with AC-TAM. This adjuvant treatment regimen represents a valid option in this group of patients.

\section{Acknowledgements}

The abstract was presented at The Primary Therapy of Early Breast Cancer 15th St. Gallen International Breast Cancer Conference 15-18 March 2017 in Vienna, Austria and published as abstract no. P007 in The Breast 32 (Suppl 1): 2017. The authors would like to thank Miss Surat Phumphuang (Division of Head Neck and Breast Surgery, Department of Surgery, Faculty of Medicine, Siriraj Hospital, Mahidol University), for coordination of the research work.

\section{Funding}

No funding was received.

\section{Availability of data and materials}

The datasets generated and/or used during this study are available from the corresponding author on reasonable request.

\section{Authors' contributions}

DS performed the statistical analysis, manuscript preparation, revised and completed the manuscript for important content. TK collected the patient data, and performed the statistical analysis and manuscript preparation. WP helped with the study design, data acquisition and manuscript preparation, and revised the manuscript. PO was involved in the treatment of the patients, provided ideas, and contributed to the conception and design of the study, the critical point of discussion and the completion of the manuscript.

\section{Ethics approval and consent to participate}

The present study was approved by the Siriraj Institutional Review Board (certificate of approval no. Si 674/2016). No informed consent was obtained from the patients as the present study was retrospective in nature.

\section{Patient consent for publication}

Not applicable as the present study was retrospective in nature.

\section{Competing interests}

The authors declare that they have no competing interests.

\section{References}

1. Torre LA, Bray F, Siegel RL, Ferlay J, Lortet-Tieulent J and Jemal A: Global cancer statistics, 2012. CA Cancer J Clin 65: 87-108, 2015.

2. Tan BK, Lim GH, Czene K, Hall P and Chia KS: Do Asian breast cancer patients have poorer survival than their western counterparts? A comparison between Singapore and Stockholm. Breast Cancer Res 11: R4, 2009.

3. Sa-Nguanraksa D, Chuangsuwanich T, Pongpruttipan T, Kummalue $\mathrm{T}$, Rojananin $\mathrm{S}$, Ratanawichhitrasin $\mathrm{A}$, Prasarttong-Osoth $\mathrm{P}$, Chuthatisith $\mathrm{S}$, Pisarnturakit $\mathrm{P}$, Aeumrithaicharoenchok W, et al: Vascular endothelial growth factor $634 \mathrm{G} / \mathrm{C}$ polymorphism is associated with increased breast cancer risk and aggressiveness. Mol Med Rep 8: 1242-1250, 2013.

4. National Cancer Institute. Hospital-Based Cancer Registry 2017. Available at http://www.nci.go.th/th/File download/Nci\%20Cancer\%20Registry/HOSPITAL-BASED\%20 2016\%20Revise\%204\%20Final.pdf. Accessed December 4, 2018.

5. Lertsanguansinchai $\mathrm{P}$, Chottetanaprasith T, Chatamra K, Sampatanukul P, Wannakrairot P, Rojpornpradit P, Shotelersuk K, Lertbutsayanukul C, Boonjunwetwat D and Vajragupta L: Estrogen and progesterone receptors status in Thai female breast cancer patients: An analysis of 399 cases at King Chulalongkorn Memorial Hospital. J Med Assoc Thai 85 (Suppl 1): S193-S202, 2002.

6. Johnston SJ and Cheung KL: Endocrine therapy for breast cancer: A model of hormonal manipulation. Oncol Ther 6: 141-156, 2018.

7. National Comprehensive Cancer Network. NCCN Clinical Practice Guidelines in Oncology (NCCN GuidelinesR): Breast Cancer. Available at https://www.ncen.org/professionals/physician gls/pdf/breast.pdf. Accessed December 4, 2018.

8. Coates AS, Keshaviah A, Thürlimann B, Mouridsen H, Mauriac L, Forbes JF, Paridaens R, Castiglione-Gertsch M, Gelber RD, Colleoni M, et al: Five years of letrozole compared with tamoxifen as initial adjuvant therapy for postmenopausal women with endocrine-responsive early breast cancer: Update of study BIG 1-98. J Clin Oncol 25: 486-492, 2007.

9. Arimidex, Tamoxifen, Alone or in Combination (ATAC) Trialists' Group, Forbes JF, Cuzick J, Buzdar A, Howell A, Tobias JS and Baum M: Effect of anastrozole and tamoxifen as adjuvant treatment for early-stage breast cancer: 100-month analysis of the ATAC trial. Lancet Oncol 9: 45-53, 2008.

10. Ovarian ablation in early breast cancer: Overview of the randomised trials. Early Breast Cancer Trialists' Collaborative Group. Lancet 348: 1189-1196, 1996.

11. Adjuvant ovarian ablation versus CMF chemotherapy in premenopausal women with pathological stage II breast carcinoma: The Scottish trial. Scottish Cancer Trials Breast Group and ICRF Breast Unit, Guy's Hospital, London. Lancet 341: 1293-1298, 1993.

12. Ejlertsen B, Dombernowsky P, Mouridsen HT, Kamby C; American Society of Clinical Oncology: Comparable effect of ovarian (OA) and CMF chemotherapy in premenopausal hormonal receptor positive breast cancer patients (PRP). Proc Am Soc Clin Oncol 18: 66a (abstract), 1999. https://www.tib.eu/ en/search/id/BLCP\%3ACN030034114/Comparable-Effect-ofOvarian-Ablation-OA-and-CMF.

13. Boccardo F, Rubagotti A, Amoroso D, Mesiti M, Romeo D, Sismondi P, Giai M, Genta F, Pacini P, Distante V, et al: Cyclophosphamide, methotrexate, and fluorouracil versus tamoxifen plus ovarian suppression as adjuvant treatment of estrogen receptor-positive pre-/perimenopausal breast cancer patients: Results of the Italian Breast Cancer Adjuvant Study Group 02 randomized trial. boccardo@hp380.ist.unige.it. J Clin Oncol 18: 2718-2727, 2000.

14. Jakesz R, Hausmaninger H, Samonigg H, Kubista E, Depisch D, Fridrik M, Stierer M, Gnant M, Steger G, Kolb R, et al: Comparison of adjuvant therapy with tamoxifen and goserelin vs. CMF in premenopausal stage I and II hormone-responsive breast cancer patients: Four-year results of Austrian Breast Cancer Study Group (ABCSG) trial 5. Eur J Cancer 35 (Suppl 4): S83, 1999.

15. Jakesz R, Hausmaninger H, Kubista E, Gnant M, Menzel C, Bauernhofer T, Seifert M, Haider K, Mlineritsch B, Steindorfer $\mathrm{P}$, et al: Randomized adjuvant trial of tamoxifen and goserelin versus cyclophosphamide, methotrexate, and fluorouracil: Evidence for the superiority of treatment with endocrine blockade in premenopausal patients with hormone-responsive breast cancer-Austrian Breast and Colorectal Cancer Study Group Trial 5. J Clin Oncol 20: 4621-4627, 2002. 
16. Roché H, Kerbrat P, Bonneterre J, Fargeot P, Fumoleau P, Monnier A, Clavère P, Goudier MJ, Chollet $P$, Guastalla JP and Serin D: Complete hormonal blockade versus epirubicin-based chemotherapy in premenopausal, one to three node-positive, and hormone-receptor positive, early breast cancer patients: 7-year follow-up results of French Adjuvant Study Group 06 randomised trial. Ann Oncol 17: 1221-1227, 2006.

17. Francis PA, Regan MM,Fleming GF, Láng I, Ciruelos E, Bellet M, Bonnefoi HR, Climent MA, Da Prada GA, Burstein HJ, et al: Adjuvant ovarian suppression in premenopausal breast cancer. N Engl J Med 372: 436-446, 2015.

18. Bloom HJ and Richardson WW: Histological grading and prognosis in breast cancer; a study of 1,409 cases of which 359 have been followed for 15 years. Br J Cancer 11: 359-377, 1957.

19. Elston CW and Ellis IO: Pathological prognostic factors in breast cancer. I. The value of histological grade in breast cancer: Experience from a large study with long-term follow-up. Histopathology 19: 403-410, 1991.

20. Chow SC, Shao J and Wang H: Sample size calculations in clinical research. Marcel Dekker, New York, 2003.

21. Jonat W, Kaufmann M, Sauerbrei W, Blamey R, Cuzick J, Namer M, Fogelman I, de Haes JC, de Matteis A, Stewart A, et al: Goserelin versus cyclophosphamide, methotrexate, and fluorouracil as adjuvant therapy in premenopausal patients with node-positive breast cancer: The Zoladex Early Breast Cancer Research Association Study. J Clin Oncol 20: 4628-4635, 2002.

22. Kaufmann M, Graf E, Jonat W, Eiermann W, Vescia S, Geberth M, Conrad B, Gademann G, Albert US, Loibl S, et al: A randomised trial of goserelin versus control after adjuvant, risk-adapted chemotherapy in premenopausal patients with primary breast cancer-GABG-IV B-93. Eur J Cancer 43: 2351-2358, 2007.

23. Early Breast Cancer Trialists' Collaborative Group (EBCTCG): Effects of chemotherapy and hormonal therapy for early breast cancer on recurrence and 15-year survival: An overview of the randomised trials. Lancet 365: 1687-1717, 2005.

24. Francis PA, Pagani O, Fleming GF, Walley BA, Colleoni M, Láng I, Gómez HL, Tondini C, Ciruelos E, Burstein HJ, et al: Tailoring adjuvant endocrine therapy for premenopausal breast cancer. N Engl J Med 379: 122-137, 2018.

25. Davidson NE, O'Neill AM, Vukov AM, Osborne CK, Martino S, White DR and Abeloff MD: Chemoendocrine therapy for premenopausal women with axillary lymph node-positive, steroid hormone receptor-positive breast cancer: Results from INT 0101 (E5188). J Clin Oncol 23: 5973-5982, 2005.

26. Ejlertsen B, Mouridsen HT, Jensen MB, Bengtsson NO, Bergh J, Cold S, Edlund P, Ewertz M, de Graaf PW, Kamby C and Nielsen DL: Similar efficacy for ovarian ablation compared with cyclophosphamide, methotrexate, and fluorouracil: From a randomized comparison of premenopausal patients with node-positive, hormone receptor-positive breast cancer. J Clin Oncol 24: 4956-4962, 2006.

27. International Breast Cancer Study Group (IBCSG), Castiglione-Gertsch M, O'Neill A, Price KN, Goldhirsch A, Coates AS, Colleoni M, Nasi ML, Bonetti M and Gelber RD: Adjuvant chemotherapy followed by goserelin versus either modality alone for premenopausal lymph node-negative breast cancer: A randomized trial. J Natl Cancer Inst 95: 1833-1846, 2003.

28. Kaufmann M, Jonat W, Blamey R, Cuzick J, Namer M, Fogelman I, de Haes JC, Schumacher M and Sauerbrei W, Zoladex Early Breast Cancer Research Association (ZEBRA) Trialists' Group: Survival analyses from the ZEBRA study. goserelin (Zoladex) versus CMF in premenopausal women with node-positive breast cancer. Eur J Cancer 39: 1711-1717, 2003.

29. Schmid P, Untch M, Kossé V, Bondar G, Vassiljev L, Tarutinov V, Lehmann U, Maubach L, Meurer J, Wallwiener D and Possinger K: Leuprorelin acetate every-3-months depot versus cyclophosphamide, methotrexate, and fluorouracil as adjuvant treatment in premenopausal patients with node-positive breast cancer: The TABLE study. J Clin Oncol 25: 2509-2515, 2007.

30. Thomson CS, Twelves CJ, Mallon EA and Leake RE; Scottish Cancer Trials Breast Group; Scottish Cancer Therapy Network: Adjuvant ovarian ablation vs. CMF chemotherapy in premenopausal breast cancer patients: Trial update and impact of immunohistochemical assessment of ER status. Breast 11: 419-429, 2002
31. von Minckwitz G, Graf E, Geberth M, Eiermann W, Jonat W, Conrad B, Brunnert K, Gerber B, Vescia S, Wollert J and Kaufmann M: CMF versus goserelin as adjuvant therapy for node-negative, hormone-receptor-positive breast cancer in premenopausal patients: A randomised trial (GABG trial IV-A-93). Eur J Cancer 42: 1780-1788, 2006.

32. de Haes H, Olschewski M, Kaufmann M, Schumacher M, Jonat W and Sauerbrei W; Zoladex Early Breast Cancer Research Association Trialists Group: Quality of life in goserelin-treated versus cyclophosphamide + methotrexate + fluorouracil-treated premenopausal and perimenopausal patients with node-positive, early breast cancer: The Zoladex Early Breast Cancer Research Association Trialists Group. J Clin Oncol 21: 4510-4516, 2003.

33. Hürny C, Bernhard J, Coates AS, Castiglione-Gertsch M, Peterson HF, Gelber RD, Forbes JF, Rudenstam CM, Simoncini E, Crivellari D, et al: Impact of adjuvant therapy on quality of life in women with node-positive operable breast cancer. International Breast Cancer Study Group. Lancet 347: 1279-1284, 1996.

34. Nystedt M, Berglund G, Bolund C, Fornander T and Rutqvist LE: Side effects of adjuvant endocrine treatment in premenopausal breast cancer patients: A prospective randomized study. J Clin Oncol 21: 1836-1844, 2003.

35. Boccardo F, Rubagotti A, Amoroso D, Sismondi P, Genta F, Nenci I, Piffanelli A, Farris A, Castagnetta L, Traina A, et al: Chemotherapy versus tamoxifen versus chemotherapy plus tamoxifen in node-positive, oestrogen-receptor positive breast cancer patients. An update at 7 years of the 1st GROCTA (Breast Cancer Adjuvant Chemo-Hormone Therapy Cooperative Group) trial. Eur J Cancer 28: 673-680, 1992.

36. Roché H, Mihura J, de Lafontan B, Reme-Saumon M, Martel P, Dubois JB and Naja A: PP-5-6 castration and tamoxifen versus chemotherapy (FAC) for premenopausal, node and receptors positive breast cancer patients: A randomized trial with a 7 years median follow up. Eur J Cancer 32 (Suppl 2): S35, 1996.

37. Bernhard J, Zahrieh D, Castiglione-Gertsch M, Hürny C, Gelber RD, Forbes JF, Murray E, Collins J, Aebi S, Thürlimann B, et al: Adjuvant chemotherapy followed by goserelin compared with either modality alone: The impact on amenorrhea, hot flashes, and quality of life in premenopausal patients-the International Breast Cancer Study Group Trial VIII. J Clin Oncol 25: 263-270, 2007.

38. Partridge AH, Burstein HJ and Winer EP: Side effects of chemotherapy and combined chemohormonal therapy in women with early-stage breast cancer. J Natl Cancer Inst Monogr 135-142, 2001.

39. Kim HJ, Lee JS, Park EH, Lim WS, Sei JY, Koh BS, Son BH, Ahn JH, Jeong KH, Kim SB and Ahn SH: Short term results from GHRH analogue use in pre-menopausal breast cancer in Korea. Eur J Surg Oncol 35: 936-941, 2009.

40. Sohn G, Ahn SH, Kim HJ, Son BH, Lee JW, Ko BS, Lee Y, Lee SB and Baek S: Survival outcome of combined GnRH agonist and tamoxifen is comparable to that of sequential adriamycin and cyclophosphamide chemotherapy plus tamoxifen in premenopausal patients with lymph-node-negative, hormone-responsive, HER2-negative, T1-T2 breast cancer. Cancer Res Treat 48 1351-1362, 2016

41. Cheng TF, Wang JD and Uen WC: Cost-utility analysis of adjuvant goserelin (Zoladex) and adjuvant chemotherapy in premenopausal women with breast cancer. BMC Cancer 12: 33, 2012.

42. Florescu M, Cinteza M and Vinereanu D: Chemotherapy-induced cardiotoxicity. Maedica (Buchar) 8: 59-67, 2013.

43. Masuda N, Iwata H, Rai Y, Anan K, Takeuchi T, Kohno N, Takei H, Yanagita Y and Noguchi S: Monthly versus 3-monthly goserelin acetate treatment in pre-menopausal patients with estrogen receptor-positive early breast cancer. Breast Cancer Res Treat 126: 443-451, 2011. 